to handle them and to induce them to regenerate viable plants. Protoplast fusion is considered as a way to by-pass obstacles to sexual hybridisation between plants which belong to different species or even genera. Although the derived product is likely to be sterile there is the possibility that successive rounds of tissue culture and regeneration may give rise to sufficient fertility to open the way to worthwhile introgression.

A number of papers deal with the approach to gene transfer by alternative means. Progress in this field is so fast that 1984 may seem like the distant past but the report of successful transfer of the $A d h l$ gene from maize into tobacco by the Agrobacterium method is at least of historical interest.

Although the frontier in the genetic manipulation of plants has been pushed forward since the date of this symposium, the advance is very uneven. There is so much information packed into the 440 pages of this attractively produced and clearly illustrated report that anyone concerned with virtually any aspect of haploid induction, somaclonal variation, somatic morphogeneis, the behaviour of protoplasts and related topics would need it as a handy reference text.

FORBES W. ROBERTSON 41 Braid Farm Road Edinburgh EH10 6LE

\section{Merino Improvement Programs in Australia. Pro- ceedings of a National Symposium, Leura, New South Wales 1987. Supervising editor, B. J. Mc- Guirk. Australian Wool Corporation, Melbourne. 535 pages. ISBN 0642115311}

An effective animal breeding programme requires sound objectives, a good scientific foundation and efficient organisation. The geneticist can help the breeder to think rationally about objectives, can provide the scientific basis of the programme and a breeding structure which can be operated effectively. This volume is the proceedings of a symposium conducted as part of a review of research on genetic improvement of sheep. The authors are all based in Australia, the breeding objectives are set in the Australian merino breeding context, and the work reported is largely Australian, but the coverage is sufficiently comprehensive to be of interest to a wider audience. In particular, all facets likely to be relevant, from defining objectives and techniques of recording to genetics of disease resistance and gene transfer are discussed. It is an unusual volume in that it comprises over 50 chapters dealing with what many geneticists might regard as the rather limited field of sheep breeding, but it serves to help applied breeders in designing their programmes and to bring them and the researchers up to date.

The broad aim is exposition and review, rather than to break new ground or provide basic analyses. There is very little mathematics presented, and the book should, for the most part, be accessible to a nontechnical audience. I would contrast, however, the discussions of genetic variation in disease resistance by Nicholas and in fly strike resistance by Raadsma and Rogan which do take pains to be generally understandable, with that by Molloy et al. on antisense RNA and gene regulation, which does not. The breadth and level of treatment is such that the book gives overall an air of worthiness rather than excitement.

As some guide to content, the section headings are (1) Breeding objectives (2) Servicing industry needs (3) Measures of progress and factors affecting progress (4) Technical knowledge-wool traits and body weight (5) Technical knowledge - reproduction (6) Technical knowledge - selection strategies (7) Technical knowledge - genetics and disease resistance (8) Exploiting all possible genetic variation (9) Physiology and genetic engineering. Editing all this was clearly a major task, and Brian McGuirk and colleagues did well to put the volume together in a coherent way.

For the Australian research geneticist, advisor or progressive breeder, this book will clearly function as the gospel for some years to come. Those from elsewhere should find it an interesting guide to the Australian breeding industry, its problems and its prospects, and to the diverse elements which have to be considered in genetic improvment programmes.

WILLIAM G. HILL Institute of Animal Genetics University of Edinburgh

Molecular Genetics of Parasitic Protozoa; Current Communications in Molecular Biology. Edited by Mervyn J. Turner and David Arnot. New York: Cold Spring Harbor Laboratory. 1988. 204 pages, Paper \$25.00. ISBN 0879693134.

Studies on the molecular biology of protozoan parasites have expanded rapidly since their inception in the late 1970's. Early work centered around a few discrete objectives in two major groups of organisms, the African trypanosomes, causative agents of sleeping sickness in man, and the Plasmodia or malaria parasites. In both groups the original objectives had much to do with the identification and cloning of parasite genes which might encode antigens which could form the basis of vaccines. In the African trypanosomes these studies centered on the variant cell surface glycoproteins (VSGs) of the blood stage trypanosomes; in Plasmodium a large number of different antigens from different stages of the parasite's life cycle have been studied; that which has received the most attention is the circumsporozoite protein (CSP) on the surface of the sporozoite stage inoculated into the blood stream of a human host by an infected anopheline mosquito. In spite of the similar aspirations of the vaccine development behind the studies 